\title{
Cloning of Saccharomyces cerevisiae DNA Replication Genes: Isolation of the $C D C 8$ Gene and Two Genes That Compensate for the $c d c 8-1$ Mutation
}

\author{
CHIA-LAM KUO AND JUDITH L. CAMPBELL* \\ Department of Chemistry, California Institute of Technology, Pasadena, California 91125
}

Received 11 April 1983/Accepted 13 July 1983

\begin{abstract}
The $C D C 8$ gene, whose product is required for DNA replication in Saccharomyces cerevisiae, has been isolated on recombinant plasmids. The yeast vector YCp50 bearing the yeast $A R S 1, C E N 4$, and URA3 sequences, to provide for replication, stability, and selection, respectively, was used to prepare a recombinant plasmid pool containing the entire yeast genome. Plasmids capable of complementing the temperature-sensitive $c d c 8-1$ mutation were isolated by transformation of a $c d c 8-1$ mutant and selection for clones able to.grow at the nonpermissive temperature. The entire complementing activity is carried on a 0.75-kilobase fragment, as revealed by deletion mapping. This fragment lies 1 kilobase downstream from the well-characterized sup4 gene, a gene known to be genetically linked to $C D C 8$, thus confirming that the cloned gene corresponds to the chromosomal $C D C 8$ gene. Two additional recombinant plasmids that complement the $c d c 8-1$ mutation but that do not contain the 0.75 -kilobase fragment or any flanking DNA were also identified in this study. These plasmids may contain genes that compensate for the lack of $C D C 8$ gene product.
\end{abstract}

The CDC8 protein of Saccharomyces cerevisi$a e$ is essential for chromosomal replication in vivo and is required for cell division. When the temperature-sensitive $c d c 8$ mutant is grown at the permissive temperature, $23^{\circ} \mathrm{C}$, and then shifted to the restrictive temperature, $36^{\circ} \mathrm{C}$, cells accumulate that contain a nucleus located at the isthmus between parent cell and bud, but which do not divide. The first wave of DNA synthesis after shift up does not occur (8). The product of the $C D C 8$ gene is apparently required throughout the period of DNA synthesis, since synchronized cultures of cells defective in the gene cease nuclear DNA replication when shifted to $36^{\circ} \mathrm{C}$ within the $\mathrm{S}$ period (9). Mitochondrial DNA replication also ceases at the nonpermissive temperature in $c d c 8$ mutants (22), and replication of the $2-\mu \mathrm{m}$ circle plasmid is defective in $c d c 8$ mutants (17).

Recently the CDC8 protein has been purified to homogeneity, using in vitro replication systems $(1,15)$. The purified protein binds to singlestranded DNA and stimulates DNA polymerase I activity on single-stranded DNA templates. The CDC8 protein may be identical to protein C, discovered by Chang et al. (4).

To carry out detailed biochemical and functional characterization of an enzyme involved in DNA replication, it is necessary to obtain large quantities of purified protein. In Escherichia coli, one way to overcome the problem of low yield of replication proteins is to clone the gene coding for a given protein into temperatureinducible bacteriophage lambda vectors or into a high-copy-number plasmid. Overproduction of the replication proteins DNA polymerase I (12), DNA ligase (23), and dnaC protein (13) has been achieved. Overproduction of the LEU2 gene product in yeast strains carrying the $L E U 2$ gene on an autonomously replicating, high-copy-number plasmid has also been achieved (10). Therefore, the same approach used in $E$. coli is applicable in yeast.

In this communication we report the molecular cloning of the $C D C 8$ gene as the first step toward overproducing the CDC8 protein and studying the regulation of expression of the gene. We were able to select stable hybrid plasmids containing the $C D C 8$ sequence from a yeast DNA library on the basis of their ability to complement a temperature-sensitive mutation in yeast transformation experiments. The identity of these genes with $C D C 8$ was confirmed by demonstration that the plasmids carrying them also carry the sup4 gene, which is known to be linked to $C D C 8$ in the chromosome.

\section{MATERIALS AND METHODS}

Strains and plasmids. The recipient in the transformations used to isolate and study the $c d c 8$ gene was strain CLK6 (ura3 trpl cdc8-1). This strain was constructed by mating strain 198 (MATa $c d c 8-1)$ with 
strain SRGO5-1 (MAT 2 trpl-1 met8-1 ile-l ilv-2) from Steve Reed (University of California at Santa Barbara). After MAT $\alpha$ trpl $c d c 8-1$ spores were identified, they were crossed with strain SS111 (MATa trpl-289 ura3-1 ura3-2 his3-532 ade2-10 gal2) from Stewart Scherer, California Institute of Technology, Pasadena. Strain 198 was provided by L. H. Hartwell. S288C (wild type) was the source of DNA for the construction of the yeast DNA library. $E$. coli MC1061 $\mathrm{F}^{-} \lambda^{-}$ araDl39 $\Delta$ (ara-leu)7697 lacX74 galU galK hsdR hsdM strA was used to propagate the library. Plasmid YCp50, a gift of Stewart Scherer, is shown in Fig. 1 and described in Results.

Medium. Yeast extract-peptone-dextrose (YPD) or synthetic minimal medium used for the culture of yeast cells is described in reference $25 . E$. coli cells were grown in L broth or M9 medium (19).

Nucleic acids. Plasmid DNAs from E. coli were prepared as described previously (6). Total yeast DNA was purified by minor modifications of the procedures of Sherman et al. (25). Small-scale and rapid isolation of plasmid DNAs from yeast were carried out as described by Nasmyth and Reed (21). BamHI linkers and $X$ hol linkers were obtained from New England Biolabs. Deoxyribonucleoside triphosphates were obtained from P-L Biochemicals.

Enzymes. All restriction enzymes were obtained from New England Biolabs or Bethesda Research Laboratories and were used according to the supplier's instructions. T4 DNA ligase and calf alkaline phosphatase were generously provided by C. C. Richardson and N. D. Hershey. Bal 31 nuclease, T4 polynucleotide kinase, and $E$. coli Klenow fragment were obtained from Bethesda Research Laboratories. Conditions for enzymatic reactions are as described by Maniatis et al. (18).

Construction of a pool of yeast DNA sequences in the centromere-containing vector $\mathrm{YCp50}$. A pool of $\mathrm{YCp} 50$ plasmids bearing yeast DNA fragments was constructed as follows. Purified yeast DNA from S288C was cleaved with three different concentrations of Sau3A $(0.02,0.06$, and $0.09 \mathrm{U} / \mu \mathrm{g}$ of DNA) so that its average size was approximately 10 kilobases $(\mathrm{kb})$. It was then pooled and fractionated on 10 to $40 \%$ sucrose density gradients as described by Maniatis et al. (18). Fragments between 5 and $20 \mathrm{~kb}$ were purified and then ligated to YCp50 DNA that had been digested with Bam HI and treated with calf alkaline phosphatase. The DNA concentrations in the ligase reaction were 50 and $10 \mu \mathrm{g} / \mathrm{ml}$. After incubation for $15 \mathrm{~h}$ at $14^{\circ} \mathrm{C}$, the ligation reaction mixture was used to transform $E$. coli strain MC1061 to ampicillin resistance by the procedures described by Dagert and Ehrlich (5). The 0.1-ml ligation mixture produced $7.9 \times 10^{4} \mathrm{Amp}^{\mathrm{r}}$ colonies, of which $75 \%$ were $\mathrm{Tet}^{\mathrm{s}}$, indicating that $75 \%$ of the transformants contained inserts or deletions at the BamHI site. The transformant colonies were scraped from the ampicillin plates, and the cells were pooled and collected by centrifugation and stored as described by Nasmyth and Reed (21).

Another recombinant plasmid pool containing yeast DNA sequences in plasmid YRp7 (21) was kindly supplied by Steven Reed and was also used in this study. YRp7 contains yeast $A R S I T R P I$ sequences but no centromere.

Yeast transformation. DNA transformation of lithium acetate-treated yeast cells, first described by Ito et

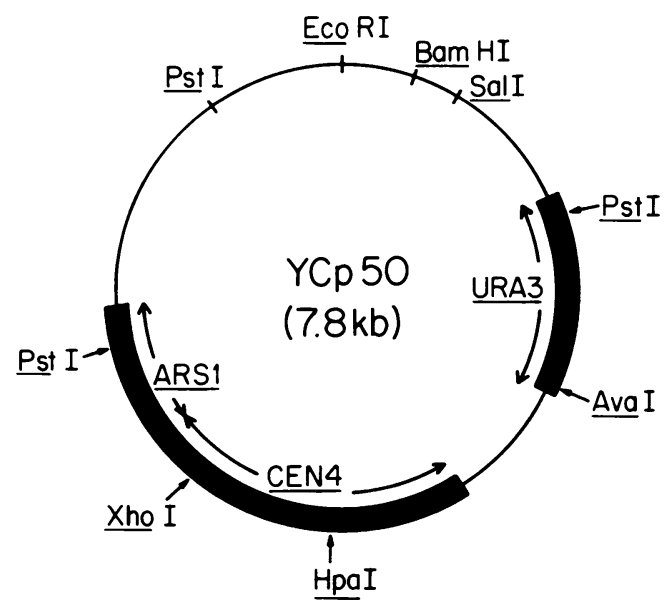

FIG. 1. Restriction map of the centromere-containing plasmid YCp50. The thin lines represent pBR322 DNA sequences; the thick lines represent yeast DNA sequences.

al. (11), was used in this study. Strains were grown to an absorbance at $590 \mathrm{~nm}$ of 1 to 2 in YPD medium. Cells were harvested by centrifugation at $8,000 \mathrm{rpm}$ (Sorvall RC5b centrifuge) for $6 \mathrm{~min}$, washed once in water, and again collected by centrifugation. The pellet was suspended in $0.1 \mathrm{M}$ lithium acetate $(0.2$ original volume) and incubated at $30^{\circ} \mathrm{C}$ for $30 \mathrm{~min}$. The cells were collected by centrifugation and resuspended in $0.1 \mathrm{M}$ lithium acetate ( 0.01 original volume). Cells were divided into $0.05-\mathrm{ml}$ aliquots and DNA was added. After $30 \mathrm{~min}$ at $30^{\circ} \mathrm{C}, 0.6 \mathrm{ml}$ of polyethylene glycol 4000 (Sigma Chemical Co.) in 0.01 M Trishydrochloride $(\mathrm{pH} 7.5)$ was added. Incubation was continued for $60 \mathrm{~min}$ at $30^{\circ} \mathrm{C}$ followed by $5 \mathrm{~min}$ at $42^{\circ} \mathrm{C}$. Each 0.6-ml mixture was divided and spread on three petri plates containing the appropriate selective media. The hybrid molecules containing ARSI and CEN4 transformed yeast at high frequency $(4,000$ to 5,000 transformants per $\mu \mathrm{g}$ of DNA), and the resulting transformants were highly stable.

Localization of the minimal cdc8-complementing DNA fragment. The minimum sequence that complemented the $c d c 8$ mutation was identified by using $\mathrm{Bal}$ 31 deletion analysis of the originally isolated plasmids. Plasmid DNA ( $3 \mu \mathrm{g})$ containing the $c d c 8$ insert (Fig. 2) was cut with $B a m \mathrm{HI}$ restriction enzyme and then treated with $0.48 \mathrm{U}$ of $\mathrm{Bal} 31$ nuclease. After 2, 3, 4, 5, and $7 \mathrm{~min}$, aliquots were removed, combined, and extracted with phenol. The DNA was incubated with the large fragment of $E$. coli DNA polymerase I and deoxyribonucleoside triphosphates to ensure that the ends were fully base paired. Bam HI linkers were then phosphorylated, using polynucleotide kinase, and phosphorylated linkers were incubated with the $\mathrm{Bal}$ 31-digested fragments in the presence of T4 DNA ligase. The respective DNA concentrations were 20 and $50 \mu \mathrm{g} / \mathrm{ml}$. After ligation, a 10-fold excess of $B a m H I$ restriction enzyme was added to cleave the linkers. The DNA fragments with BamHI sticky ends were separated from the free linkers by gel filtration as described in reference 18 . Ring closure was carried out 

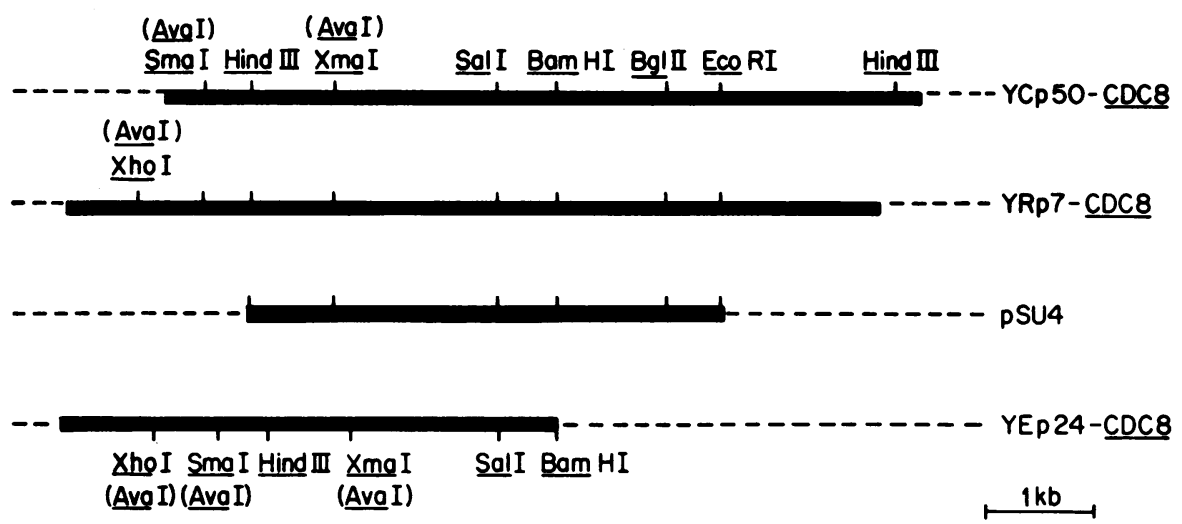

FIG. 2. Restriction map of $C D C 8$-containing inserts in YCp50 CDC8, YRp7 CDC8, YEp24 CDC8, and pSU4. The four inserts are drawn so that their overlapping regions are aligned. The dashed line represents a portion of vector sequences. The sizes of the various restriction fragments were estimated from gel electrophoresis. pSU4 was originally constructed by ligating a yeast EcoRI-HindIII fragment containing the SUP4 gene into plasmid pBR322 (7). The single $X m a I$ site on pSU4 is located near the $3^{\prime}$ end of the cloned tRNA ${ }^{\text {Tyr }}$ gene.

in the presence of T4 DNA ligase, and the ligation mixture was used for transformation of $E$. coli cells. Individual transformants were grown in 5-ml cultures, DNA was prepared, and the structure of the resultant plasmids was examined by gel electrophoresis after treatment with appropriate restriction enzymes. Plasmids containing deletions ranging from 50 to 500 base pairs (bp) were chosen for complementation testing by transformation of yeast.

DNA of the plasmid containing the 255-bp deletion (YpCLK255) was purified, and a second round of $\mathrm{Bal}$ 31 digestion was carried out from the opposite side of the CDC8 fragment. YpCLK255 was digested with $X$ hol, $B a l 31$ digestions were carried out, and Xhol linkers were joined to the deleted DNAs. These deletions were religated and analyzed as above. The smallest insert that complemented $c d c 8$ was approximately $0.75 \mathrm{~kb}$. The final plasmid is called YpCLK1.

Other procedures. Procedures for nick translation, gel electrophoresis, and blot hybridization were those described by Maniatis et al. (18).

\section{RESULTS}

Construction of a yeast DNA library in a centromere-containing vector. The vector chosen for the construction of the yeast library was the hybrid plasmid YCp50 (Fig. 1). YCp50 contains the replication origin of $\mathrm{pBR} 322$ and the genes for $\mathrm{Amp}^{\mathrm{r}}$ and $\mathrm{Tet}^{\mathrm{r}}$. Insertion into the BamHI site of YCp50 renders the plasmid $\mathrm{Tet}^{\mathrm{s}}$. YCp50 also contains a yeast replicator, $A R S I$, and a marker selectable in yeast, URA3. Finally, the plasmid contains the $1.8-\mathrm{kb}$ yeast $C E N 4$ fragment that encompasses the centromere of chromosome IV. We chose to use the centromere-containing plasmid since the transformation frequencies and stability of transformants obtained are higher than with $A R S$ - or $2-\mu \mathrm{m}$-containing vectors. This has the important consequence that each of the multiple transformations of yeast required for isolating and characterizing genes is accelerated by at least a day. Furthermore, at the outset, we did not know whether the $C D C 8$ gene would be lethal in high gene dosage. YCp50 has a copy number of 1 .

The library was constructed by a minor modification of the procedure of Nasmyth and Reed (21), as described under Materials and Methods. Since the pool contained at least $1.7 \times 10^{4}$ recombinant clones, there are approximately six yeast genomes in this library.

Isolation of $C D C 8$-containing plasmids. When used to transform CLK6 ura3 cdc8, DNA prepared from the yeast $\mathrm{YCp} 50$ hybrid pool yielded about $10^{3} \mathrm{URA}^{+}$transformants per $\mu \mathrm{g}$, of which $0.04 \%$ were able to grow at the nonpermissive temperature $\left(37^{\circ} \mathrm{C}\right)$. DNA was prepared from four of the yeast $\mathrm{URA}^{+} \mathrm{CDC}^{+}$transformants and introduced into $E$. coli by transformation to ampicillin resistance. Plasmid DNA was prepared from Amp transformants and analyzed by digestion with restriction endonuclease followed by agarose gel electrophoresis. Since the four plasmids all had identical restriction enzyme maps, only one, YCp50 CDC8, was chosen for further study.

In a second set of experiments, DNA prepared from the yeast YRp7 hybrid pool described previously by Nasmyth and Reed (21) was used to transform CLK6 trpl $c d c 8$. Five interesting $T R P^{+} C D C^{+}$transformants were isolated. Restriction enzyme mapping indicated that three of these were identical and homologous with the YCp50 clones (see Fig. 2), and they were therefore designated YRp7 CDC8. Two others, discussed separately below, contained two different inserts and were not homologous to the YCp50 insert.

Finally, L. H. Hartwell had independently 
TABLE 1. Transformation of $c d c 8$ strain (CLK6) with purified plasmids ${ }^{a}$

\begin{tabular}{|c|c|c|}
\hline \multirow{2}{*}{ Plasmid } & \multicolumn{2}{|c|}{ Colonies capable of growth } \\
\hline & $23^{\circ} \mathrm{C}$ & $37^{\circ} \mathrm{C}$ \\
\hline YCp50 CDC8 & $2 \times 10^{3}$ & $2 \times 10^{3}$ \\
\hline YRp7 CDC8 & $2.1 \times 10^{3}$ & $1.9 \times 10^{3}$ \\
\hline YEp24 CDC8 & $1.9 \times 10^{3}$ & $1.9 \times 10$ \\
\hline YRp7 SOC8-1 & 300 & 200 \\
\hline YRp7 SOC8-2 & 280 & 198 \\
\hline YCp50 & $4 \times 10^{3}$ & 0 \\
\hline YRp7 & $2 \times 10^{3}$ & 4 \\
\hline
\end{tabular}

${ }^{a}$ The $c d c 8$ strain was grown at $23^{\circ} \mathrm{C}$. Cells were prepared for transformation as described in the text. Transformations are reported as transformant colonies per $\mu \mathrm{g}$ of transforming DNA.

isolated, from a yeast library of S288C DNA prepared in the vector YEp24 (2), two clones containing inserts that complement $c d c 8$ at $34^{\circ} \mathrm{C}$ (personal communication). These two plasmids, YEp24 CDC8, were identical to each other.

High-efficiency transformation of $c d c 8$ mutants with cloned plasmid DNAs; stability of transformants. Purified DNAs from plasmids YCp50 $C D C 8, \mathrm{YRp} 7 C D C 8$, and YEp24 CDC8 were reintroduced into the CLK6 cdc 8 strain by transformation. In each case (Table 1), about $2 \times 10^{3}$ colonies per $\mu \mathrm{g}$ of transforming DNA were capable of growth at the restrictive temperature (selection for $\mathrm{CDC}^{+}$and $\mathrm{URA}^{+}$or $\mathrm{TRP}^{+}$), consistent with complementation by autonomous replication rather than recombination. Similar results were obtained when selecting for $\mathrm{URA}^{+}$ or $\mathrm{TRP}^{+}$at the permissive temperature $\left(23^{\circ} \mathrm{C}\right)$.

Table 2 presents data obtained from experiments to determine the mitotic stability of transformants carrying the various plasmids isolated. As expected for a centromere vector (27), $98 \%$ of the transformants bearing ARSI-CEN4 hybrid plasmids, YCp50 CDC8, maintained both $\mathrm{URA}^{+}$ and $\mathrm{CDC}^{+}$phenotypes when grown under permissive conditions for 20 generations. However, only $15 \%$ of the cells transformed by YEp24 $C D C 8$, a plasmid bearing the $2-\mu \mathrm{m}$ origin of replication, retained both $\mathrm{URA}^{+}$and $\mathrm{CDC}^{+}$ phenotypes after growing in rich media at room temperature for more than 10 generations. Unexpectedly, the $A R S I$-containing plasmid, YRp7 $C D C 8$, gave rise to transformants that showed greater stability of both the $\mathrm{TRP}^{+}$and the $\mathrm{CDC}^{+}$ properties than even the $C E N$-containing transformants. Since total yeast DNA made from $\mathrm{TRP}^{+} \mathrm{CDC}^{+}$yeast cells after growth under nonselective conditions yielded fewer than 10 $\mathrm{Amp}^{\mathrm{r}}$ colonies when used to transform $E$. coli, the plasmid appears to have integrated into the chromosome in this particular transformant during growth under permissive conditions.

Characterization of cloned inserts by restriction enzyme mapping and blot hybridization. To see whether the three independent isolates contained the same gene and to identify the region responsible for complementation, restriction enzyme maps of the respective inserts in YCp50 $C D C 8$, YRp7 $C D C 8$, and YEp24 CDC8 were derived. The plasmids contained overlapping inserts with the configurations shown in Fig. 2.

One discrepancy in the map of the overlapping region is also shown in Fig. 2. In the digest of YEp24 CDC8, there is an XmaI-SalI fragment that is approximately $150 \mathrm{bp}$ smaller than the corresponding XmaI-SalI fragment in both YRp7 CDC8 and YCp50 CDC8. Blot hybridization, however (Fig. 3), indicates that the 750-bp fragment shown below to contain the $C D C 8$ gene (Fig. 4) hybridized equally strongly to the $X m a I-S a l l$ fragments from YEp24 CDC8 and YRp7 $C D C 8$, suggesting that the 150 -bp difference in size in the YEp24 isolate was due to a deletion in an otherwise identical fragment. The region of the genome around $C D C 8$ shows a high frequency of sequence alterations when different strains are compared (3), and this may account for this polymorphism.

Linkage of the cloned genes to the SUP4 locus. The apparent homology between the inserts isolated from YCp50, YRp7, and YEp24 libraries was not alone sufficient to prove that all three contained the $C D C 8$ gene. Since the $C D C 8$ gene has been shown to be closely linked to the sup4 locus $(16,20)$, demonstration that the cloned gene came from the sup4 region of chromosome $\mathrm{X}$ would constitute better proof that it was $C D C 8$. To establish this linkage, use was made of the fact that the SUP4 gene had been previously cloned and sequenced (7).

DNA from plasmid pSU4 (7), containing a functional SUP4 gene, was digested with appro-

TABLE 2. Mitotic stability test of yeast transformants ${ }^{a}$

\begin{tabular}{lcc}
\hline \multirow{2}{*}{ Plasmid } & \multicolumn{2}{c}{ Transformed } \\
\cline { 2 - 3 } & $\begin{array}{c}10 \\
\text { generations }\end{array}$ & $\begin{array}{c}20 \\
\text { generations }\end{array}$ \\
\hline YCp50 CDC8 & 98 & 96 \\
YRp7 CDC8 & 95 & 95 \\
YEp24 CDC8 & 96 & 15 \\
YRp7 SOC8-1 & 1 & \\
YRp7 SOC8-2 & 2 & \\
\hline
\end{tabular}

a Yeast transformants were grown in selective media and diluted approximately 1/1,000 ( 10 generations) or $1 / 10^{6}$ ( $\sim 20$ generations) in either supplemented minimal media or rich media (YPD). After growth at room temperature, the mid-log-phase cultures were plated onto YPD plates, and the percentage of URA ${ }^{+}$ $\mathrm{CDC}^{+}$or $\mathrm{TRP}^{+} \mathrm{CDC}^{+}$was determined by replica plating. The values given represent an average number of several independent determinations. 


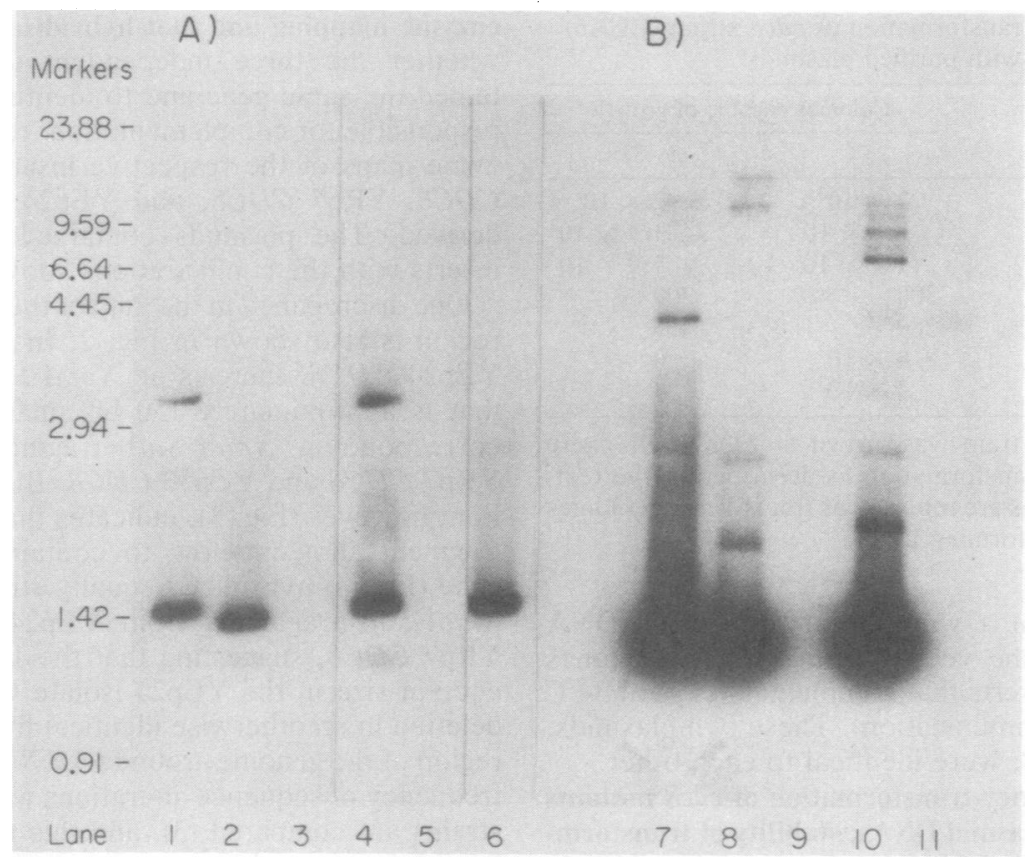

FIG. 3. Southern blot analysis of DNA sequence homology among the $C D C 8$-related plasmids. The probe in (A) was the 750-bp CDC8 fragment from YpCLK1 (Fig. 4), and the probe in (B) was the 1.17-kb AvaI fragment shown in Fig. 2, to the left of the Xmal-Sall fragment. Each lane contains a different plasmid DNA that was transferred to a nitrocellulose filter after cleavage with restriction endonucleases $S a l I$ and $A v a I$ and electrophoresis on a 1\% agarose gel. Lanes 1 and 7, YCp50 CDC8; lanes 2 and 8, YEp24 CDC8; lanes 3 and 9, YRp7 SOC8-1; lanes 4 and 10, YRp7 CDC8; lanes 5 and 11, YRp7 SOC8-2; lane 6, pSU4. Marker lengths are in kilobases.

priate restriction enzymes and analyzed by gel electrophoresis. The pSU4 plasmid contains an insert that overlaps the inserts in the $C D C 8$ plasmids by several kilobases (Fig. 2), raising the possibility that the putative $C D C 8$ clones also carried the sup4 gene. The SUP4 gene itself contains a unique $X m a I$ recognition site (7), allowing us to infer the position of the sup 4 region on the $C D C 8$ clones. Comparison of restriction maps indicates that the $X m a I$ site in the sup4 gene forms one end of the common 1.5kb XmaI-Sall fragment found in YCp50 and YRp7 derivatives and of the $1.35-\mathrm{kb}$ fragment in YEp24 CDC8. Further support for the overlap of the $C D C 8$ and SUP4 clones comes from blot hybridizations shown in Fig. 3. The 750-bp fragment from YpCLK1 (see Fig. 4) hybridized equally strongly to digests of the other $c d c 8$ complementing plasmids and to the SUP4 plasmid (Fig. 3). Previous mapping experiments show that there are no delta sequences on this probe (cf. Fig. 4 of reference 3). Similar results were obtained with the XmaI-SalI fragments from YEp24 CDC8 or YCp50 CDC8 as hybridization probes.

The mapping data were then confirmed by carrying out the converse experiment, namely, by showing that the originally isolated SUP4 clone, pSU4, also contains the $C D C 8$ gene and is capable of complementing the $c d c 8$ mutation. Since the SUP4 gene was on an integrating plasmid and since such vectors exhibit low transformation frequencies, it would be hard to distinguish complementation from reversion to temperature resistance with the original pSU4 plasmid. We therefore constructed a recombinant plasmid containing the BamHI fragment of pSU4 (Fig. 5) inserted into the BamHI site of YCp50. When the resulting plasmid was introduced into $c d c 8$ by transformation, an almost equal number of colonies was observed at 23 and $37^{\circ} \mathrm{C}$. The efficiency of transformation with this plasmid was a little lower than that with the three plasmids described above and might be due to the presence of the mutant SUP4 $t_{R N A}{ }^{T y r}$ gene in the plasmid. We conclude that the cloned sequences shown in Fig. 2 are linked to the SUP4 gene and probably carry the $C D C 8$ gene.

Minimal DNA fragment containing the $C D C 8$ gene. To identify the coding region for the $C D C 8$ gene, the DNA of the hybrid plasmids was subjected to deletion analysis in the regions considered likely, on the basis of the foregoing studies, to contain the gene. The sites chosen for Bal 31 deletion analysis and the final construc- 


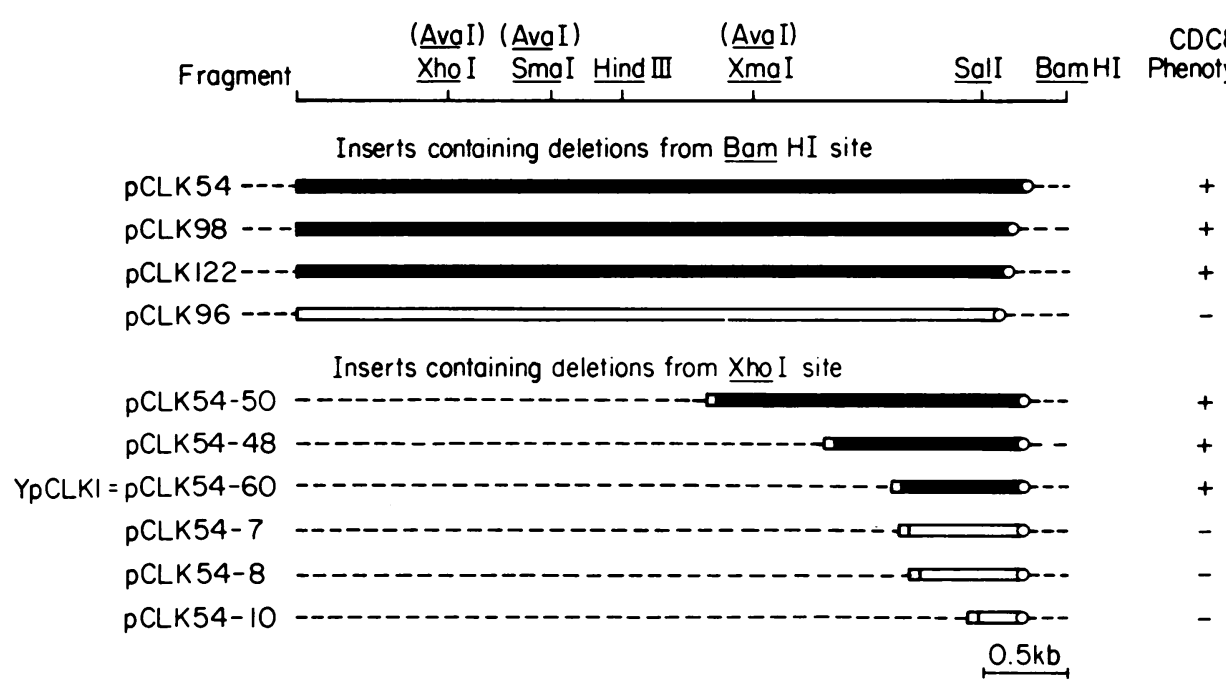

FIG. 4. Delimitation of the $C D C 8$ gene. At the top is a restriction map of the DNA containing the $C D C 8$ gene. The thick lines below the map indicate the sequences contained in each of the designated deletion mutants. The region of DNA deleted is designated by the dashed line. These deletions were constructed in vitro as described in the text. The $\mathrm{CDC}^{+}$phenotype was determined by transformation of a $c d c 8$ mutant with plasmid DNA containing each fragment. High-frequency transformation of the $c d c 8$ mutant to $\mathrm{CDC}^{+}$was indicative of $c d c 8$ gene function. Symbols: (O) BamHI ends; ( $\square) \mathrm{XhoI}$ ends.

tion of a plasmid containing the minimal complementing sequence are described in Materials and Methods and summarized in Fig. 4.

The deletion analysis reveals that the smallest fragment capable of transforming the $c d c 8 \mathrm{mu}-$ tant to temperature resistance at high frequency is $750 \mathrm{bp}$ long. This fragment contains no delta sequences and hybridizes to the XmaI-SalI fragment from all of the libraries. This region lies $<1$ $\mathrm{kb}$ away from the SUP4 gene. The close apposition of the two genes accounts for the suppression of meiotic recombination frequency reported between the two genes $(16,20)$. The transformation frequencies for a number of the deletion mutant plasmids was determined (Table 3 ). Since the high frequency of transformation observed is typical of efficiencies obtained by complementation rather than recombination, these data suggest that the small fragment is producing a functional $C D C 8$ protein or fragment thereof.

Detection of two additional genes that compensate for the $c d c 8-1$ mutation. Two of the plasmids detected in the YRp7 library contain genes that complement $c d c 8-1$, but that do not contain any sequence homology with the cloned $C D C 8$ gene described in the preceding paragraphs. First, restriction enzyme mapping using both 4- and 6bp recognition enzymes shows that the two plasmids isolated from the YRp7 library have a completely different restriction map from the plasmids discussed thus far and from each other (data not shown). Furthermore, no homology between these two plasmids and the 750-bp
CDC8-containing fragment could be detected by blot hybridization (Fig. 3, lanes 3, 5, 9, and 11). Based on the restriction enzyme mapping, we conclude that these plasmids give high-frequency transformation of the $c d c 8$ mutants at the restrictive temperature by providing either a different protein that compensates for a deficiency in CDC8 protein or a suppressor of the missense mutation in $c d c 8-1$. We have designated the genes responsible for this behavior SOC8$I$ and SOC8-2, suppressors of $c d c 8$. These plasmids transform at a lower efficiency than the CDC8-containing plasmids (see Table 1), although still at a frequency 200 to 300 times greater than an integrating plasmid. Further investigations are essential to determine how they are compensating for the defect in $C D C 8$ (see Discussion).

\section{DISCUSSION}

We have cloned a gene that complements $c d c 8$ mutants and that is physically linked to the SUP4 locus. The map position of the cloned gene confirms its identity with the CDC 8 gene. The library we have described here should also be useful in cloning genes that would be lethal in high dosage; high-frequency transformation is achieved with the centromere vector, but the intracellular copy number is 1 .

An interesting finding is that the minimum fragment capable of complementing the $c d c 8$ mutation is $750 \mathrm{bp}$ long. Since plasmids containing this small insert were able to transform with the same high frequency as plasmids containing 


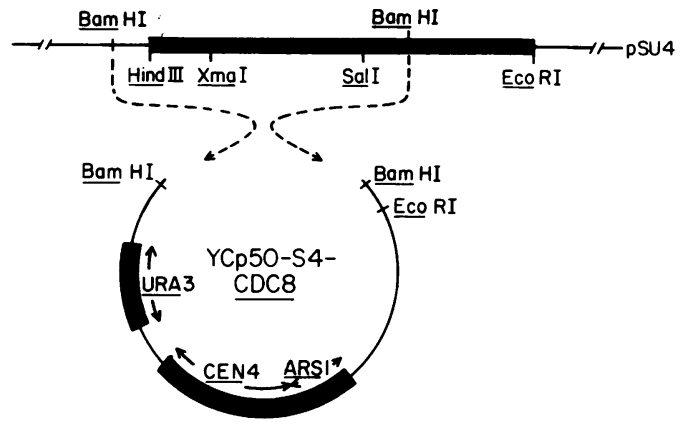

FIG. 5. Construction and structure of YCp50-S4 $C D C 8$. Plasmid pSU4 was cleaved with restriction nuclease $B a m \mathrm{HI}$, and the fragment containing the SUP4 and CDC8 genes was recloned in plasmid YCp50. YCp50 was digested with BamHI endonuclease and treated with alkaline phosphatase to prevent ligation of vector DNA in the absence of an insert. Ligations were carried out overnight at $15^{\circ} \mathrm{C}$, using $\mathrm{T} 4$ DNA ligase; the reaction mixture contained $1 \mu \mathrm{g}$ of vector DNA and $0.5 \mu \mathrm{g}$ of pSU4 in $50 \mu \mathrm{l}$ of $66 \mathrm{mM}$ Tris-hydrochloride ( $\mathrm{pH}$ 7.6)-66 mM MgCl $2-10 \mathrm{mM}$ dithiothreitol-1 mM ATP. The resulting plasmid, YCp50-S4 CDC8, was shown to contain two BamHI sites, and the orientation of the fragment inserted was determined by restriction endonuclease digestion analysis.

large segments of flanking DNAs, it appears likely that this fragment contains the complete CDC8 gene. However, such a coding region would normally only give a 27,000 -dalton protein. Using complementation assays, others have purified the CDC8 protein to homogeneity and found a monomeric molecular weight of 34,000 to 40,000 (1). It is therefore possible that we have identified a fragment of the CDC8 protein that is active either in itself or in complementing the temperature-sensitive protein in the mutant. (The possibility that the small fragment of the gene is giving transformants at $37^{\circ} \mathrm{C}$ by virtue of recombination between the plasmid and the mutant gene rather than complementation is made unlikely by the high frequency of transformation and by the facts that cells that have segregated out the URA ${ }^{+}$phenotype after growth on rich medium are once again temperature sensitive and that this segregation occurs with the frequency characteristic of autonomous plasmid loss rather than loss of integrated plasmids.) Nucleotide sequencing of the small fragment and purification of the overproduced $C D C 8$ gene product from cells containing the $C D C 8$ plasmid should resolve these questions. If, indeed, we have only identified an active fragment, this may be useful in determining whether the CDC8 protein can be described in terms of separate domains of activity, as is true of other single-stranded DNA binding proteins (14).
Northern blot analysis, not shown in this work, indicates that the $C D C 8$ gene cloned in YEp24 produces 10 times as much of a $0.9-\mathrm{kb}$ RNA that hybridizes to the $C D C 8$ gene as wildtype yeast cells. The overproduction of the RNA makes it likely the protein will be overproduced to the same extent. Since the assay for the CDC8 protein is not linear in extracts, we will have to purify the protein from strains containing the $C D C 8$ plasmids before being certain the protein itself is also overproduced.

Finally, an unexplained but potentially interesting result is the isolation of two plasmids that do not contain the $C D C 8$ gene but that do suppress the temperature-sensitive phenotype in strains carrying the plasmid. What are these genes? There are at least four testable possibilities. First, they may just be previously unidentified genetic suppressors, most likely missense suppressors. Second, and more interesting, they may encode proteins that can bypass the need for the CDC8 protein. The CDC8 protein may be a single-stranded DNA binding protein (1), and perhaps there is a second such protein in yeast that can substitute for the CDC8 protein. We have identified an independent replication mutant that is deficient in a second single-stranded DNA binding protein that might serve such a function (C. L. Kuo, N. K. Huang, and J. L. Campbell, unpublished data). Third, they might encode proteins that are positively regulated by CDC8 function. Finally, the most interesting possibility is that these sequences may represent genes for other replication proteins that interact with the CDC8 protein, and overproduction of the protein might compensate for an interaction weakened by the $c d c 8$ mutation. It is likely that the CDC8 protein does interact with other proteins since it has been shown in vitro to stimulate DNA polymerase I of yeasts (1). Such genes should be required for viability and this can be tested by creating deletion mutants in vitro,

TABLE 3. Frequency of transformation of $c d c 8(\mathrm{Ts})$ by hybrid plasmid DNA ${ }^{a}$

\begin{tabular}{lcc}
\hline \multicolumn{1}{c}{ Plasmid } & $\begin{array}{c}\text { Insert size } \\
(\mathrm{kb})\end{array}$ & $\begin{array}{c}\text { Colonies/ } \mu \mathrm{g} \text { of DNA } \\
\text { at } 37^{\circ} \mathrm{C}\end{array}$ \\
\hline pCLK54 & 4.25 & $2.9 \times 10^{3}$ \\
pCLK122 & 4.17 & $2.8 \times 10^{3}$ \\
pCLK54-48 & 1.16 & $3.1 \times 10^{3}$ \\
pCLK54-60 & 0.75 & $3 \times 10^{3}$ \\
pCLK54-42 & 0.62 & 5 \\
pCLK54-10 & 0.28 & 6 \\
\hline
\end{tabular}

${ }^{a}$ The $c d c 8(\mathrm{Ts})$ strain, CLK6, was used for yeast transformation. Before selection for colonies capable of growth at the restrictive temperature, the transformed cells were allowed to grow for $3 \mathrm{~h}$ at $23^{\circ} \mathrm{C}$ on YPD plates before placing them at the restrictive temperature. 
replacing them in the chromosome and asking whether the mutation is lethal $(24,26)$. This may offer a very powerful way of identifying new replication genes.

\section{ACKNOWLEDGMENTS}

We thank Lee Hartwell for providing us with plasmid YEp24-CDC8 before publication and for critical comments on the manuscript. We thank Stewart Scherer for plasmid YCp50 and helpful discussion.

This investigation was supported by grants from the Public Health Service National Institutes of Health (GM25508), the American Cancer Society (MV-142), and the March of Dimes (1-794). J.L.C. is the recipient of Research Career Development Award CA00544.

\section{ADDENDUM IN PROOF}

The length of the RNA encoded by the $C D C 8$ gene is $0.9 \mathrm{~kb}$. Furthermore, recent DNA sequencing in this laboratory indicates that the protein encoded by the $C D C 8$ gene is 216 amino acids in length. The molecular weight of the protein encoded by this sequence is 24,792 . Taken together with the size of the segment of DNA that gives complete complementation of the $c d c 8$ mutation, these data make it unlikely that the CDC8 protein would have a molecular weight of 37,000 , as previously estimated on the basis of mobility in SDS gels (1). The discrepancy between the molecular weight determined by DNA sequencing and that determined by analysis of the protein (1) could arise if the mobility of the protein is anomalous or if the molecular weight analysis of the protein is inaccurate for some other reason.

\section{LITERATURE CITED}

1. Arendes, J., K. C. Kim, and A. Sugino. 1983. Yeast 2- $\mu \mathrm{m}$ plasmid DNA replication in vitro: purification of the CDC8 gene product by complementation assay. Proc. Natl. Acad. Sci. U.S.A. 80:673-677.

2. Botstein, D., C. Falco, S. Stewart, M. Brennan, S. Scherer, D. Stinchcomb, K. Struhl, and R. Davis. 1979. Sterile host yeasts (SHY): a eukaryotic system of biological containment for recombinant DNA experiments. Gene 8:17-24.

3. Cameron, J. R., E. Y. Loh, and R. W. Davis. 1979. Evidence for transposition of dispersed repetitive DNA families in yeast. Cell 16:739-751.

4. Chang, L. M. S., K. Lurie, and P. Plevani. 1978. A stimulatory factor for yeast DNA polymerase. Cold Spring Harbor Symp. Quant. Biol. 43:587-595.

5. Dagert, M., and S. D. Ehrlich. 1979. Prolonged incubation in calcium chloride improves the competence of Escherichia coli cells. Gene 6:23-28.

6. Davis, R. W., D. Botstein, and J. R. Roth. 1980. Advanced bacterial genetics. Cold Spring Harbor Laboratory, Cold Spring Harbor, N.Y.

7. Goodman, H. M., M. V. Olson, and B. D. Hall. 1977. Nucleotide sequence of a mutant eukaryotic gene: the yeast tyrosine-inserting ochre suppressor SUP4-0. Proc. Natl. Acad. Sci. U.S.A. 74:5453-5457.

8. Hartwell, L. H. 1971. Genetic control of the cell division cycle in yeast. II. Genes controlling DNA replication and its initiation. J. Mol. Biol. 59:183-194.
9. Hartwell, L. H. 1973. Three additional genes required for deoxyribonucleic acid synthesis in Saccharomyces cerevisiae. J. Bacteriol. 115:966-974.

10. Hsu, Y.-P., and G. B. Kohlhaw. 1982. Overproduction and control of the LEU2 gene product, $\beta$-isopropylmalate dehydrogenase, in transformed yeast strains. J. Biol. Chem. 257:39-41.

11. Ito, H., Y. Fukuda, K. Murata, and A. Kimura. 1983. Transformation of intact yeast cells treated with alkali cations. J. Bacteriol. 153:163-168.

12. Kelly, W. S., K. Chalmers, and N. E. Murray. 1977. Isolation and characterization of a polA transducing phage. Proc. Natl. Acad. Sci. U.S.A. 74:5632-5636.

13. Kobori, J. A., and A. Kornberg. 1982. The Escherichia coli dnaC gene product. I. Overproduction of the dnaC proteins of Escherichia coli and Salmonella typhimurium by cloning into a high copy number plasmid. J. Biol. Chem. 257:13757-13762.

14. Kowalczykowski, S., D. Bear, and P. von Hippel. 1981. Single-stranded DNA binding proteins, p. 373-444. In P. D. Boyer (ed.), The enzymes, Academic Press, Inc. New York.

15. Kuo, C. L., and J. L. Campbell. 1982. Purification of the cdc8 protein of Saccharomyces cerevisiae by complementation in an aphidicolin-sensitive in vitro DNA replication system. Proc. Natl. Acad. Sci. U.S.A. 79:4243-4247.

16. Lawrence, C. W., F. Sherman, M. Jackson, and R. A. Gilmore. 1975. Mapping and gene conversion studies with the structural gene for iso-1-cytochrome $\mathrm{C}$ in yeast. Genetics 81:615-629.

17. Livingston, D. M., and D. M. Kupfer. 1977. Control of Saccharomyces cerevisiae $2 \mu \mathrm{m}$ DNA replication by cell division cycle genes that control nuclear DNA replication. J. Mol. Biol. 116:249-260.

18. Maniatis, T., E. F. Fritsch, and J. Sambrook. 1982 Molecular cloning. Cold Spring Harbor Laboratory, Cold Spring Harbor, N.Y.

19. Miller, J. H. 1972. Experiments in molecular genetics. Cold Spring Harbor Laboratory, Cold Spring Harbor, N.Y.

20. Mortimer, R. K., and D. C. Hawthorne. 1973. Genetic mapping in Saccharomyces. IV. Mapping of temperaturesensitive genes and use of disomic strains in localizing genes. Genetics 74:33-54.

21. Nasmyth, K. A., and S. I. Reed. 1979. Isolation of genes by complementation in yeast: molecular cloning of a cellcycle gene. Proc. Natl. Acad. Sci. U.S.A. 77:2119-2123.

22. Newlon, C. F., and W. L. Fangman. 1975. Mitochondrial DNA synthesis in cell cycle mutants of Saccharomyces cerevisiae. Cell 5:423-428.

23. Panasenko, S., J. Cameron, R. W. Davis, and I. R. Lehman. 1977. Five hundredfold overproduction of DNA ligase after induction of a hybrid lambda lysogen constructed in vitro. Science 196:188-189.

24. Scherer, S., and R. W. Davis. 1979. Replacement of chromosome segments with altered DNA sequences constructed in vitro. Proc. Natl. Acad. Sci. U.S.A. 76:49514955 .

25. Sherman, F., G. R. Fink, and J. Hicks. 1979. Methods in yeast genetics. Cold Spring Harbor Laboratory, Cold Spring Harbor, N.Y.

26. Shortle, D., J. E. Haber, and D. Botstein. 1982. Lethal disruption of the yeast actin gene by integrative DNA transformation. Science 217:371-373.

27. Stinchcomb, D. T., C. Mann, and R. W. Davis. 1982. Centromeric DNA from Saccharomyces cerevisiae. J. Mol. Biol. 158:157-179. 